\title{
Stem Cell Therapy: A Review
}

The human body is an intricate system consisting of numerous cells and tissues working in an organized fashion for the sustenance of life and stem cell biology become an important field for the understanding of tissue regeneration and implementation of regenerative medicine. Stem cells have capability of replicating themselves and can be readily available at the time of a planned procedure. Furthermore, it's been shown that these cells have high potential to serve as resources not for medical therapies and tissue engineering, but also for dental or bone reconstruction. Stem cell research is not merely a science fiction but has rather opened the door for future treatment modalities.

KEYWORDS: Stem cell, Cancer, Regenerative medicine, Treatment

\section{INTRODUCTION}

In today's world; lack of suitable donor organs and tissues is the biggest issue in transplantation medicine. But the existence of stem cells in our bodies solved this issue and raised hope in the medical potential of regeneration which further led to the development of bone marrow transplantation. ${ }^{1}$ Stem cell therapy is a type of interventional procedure where introduction of new cells into damaged tissue occurs in order to treat disease or injury. Even the stem cell treatments have the potential to change the face of those human beings who suffered from serious and alleviate diseases as per many of the researchers. ${ }^{1,2,3}$

\section{Application of stem cells in various treatment modalities:}

Brain damage: Within the brain; cell death occurs due to stroke and traumatic brain injury which is characterized by a loss of neurons and oligodendrocytes. Healthy brains of adults consisted of neural stem cells which has capability of division in order to maintain number of general stem cells, or become progenitor cells. Even the genetically engineered neural stem cells can also be used in the regeneration and treatment of neural diseases. Henceforth used in the treatment of mucopolysaccharide and lysosomal storage

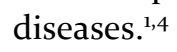

In various brain degeneration procedures, such as in Parkinson's and Alzheimer's disease,
Huntington's disease, amyotrophic lateral sclerosis, multiple sclerosis, stroke, brain tumor, glioblastoma, lysosomal storage diseases, stem cells related therapies are widely used. ${ }^{5}$

Deafness: With the use of embryonic stem cells successful re-growth of cochlea hair cells have been reported. ${ }^{6}$

Diabetes: Function of insulin-producing beta cells is lost within the pancreas of diabetic patients. In these kind of cases human embryonic stem cells plays an important role as they can be grown in cell culture and stimulated to form insulin-producing cell that can further be transplanted into the patient. ${ }^{7}$

Spinal cord injury: A Korean team of researchers led by Prof. Song Chang-Hun of Chosun University in November 2004 reported the successful transplantation of multipotent stem cells from umbilical cord blood to a 37 year old woman named Hwang Mi-Soon who sustained a spinal cord injury in 1985 . In this accidental injury her lower back and hips were damaged and she was unable to stand up or walk. The researcher's team injected the stem cells from umbilical cord blood into the damaged part of her spinal cord. After the 15 days of successful treatment her sensory and motor nerves started to improve along with movement of her hips. After 25 days, her feet responded to stimulation. ${ }^{8,9,10}$ 
Baldness: Many of the researchers predicted that stem cells may lead to success in treating baldness as hair follicles also contain stem cells which may happen through an activation of the stem cells progenitor cells. ${ }^{6}$

But this treatment happens to work by activation of already existing stem cells on the scalp. Even the later on stages treatments may be able work out by simply giving the signals to these follicle stem cells in order to send off chemical signals to nearby follicle cells which have shrunk during the aging process. At last the regeneration and formation of healthier hair in response that occurred as a result of these signals. ${ }^{11,12}$

Heart damage: It has been seen through various clinical trials that adult stem cell therapy is safe, effective, and equally efficient in treating old and recent infarcts among many of the heart problems. $^{8}$ Heart muscle cell generation, stimulation of growth of new blood vessels in order to repopulate damaged heart tissue, secretion of growth factors are the possible mechanisms of recovery of heart diseases. Moreover there are possible chances for differentiation of adult bone marrow cells into heart muscle cells. Even the human embryonic stem cells (hESC) proved to be a potential source of advances in cardiomyocyte regeneration. ${ }^{13}$

Wound healing: In an adult disorganized collagen structure, loss of hair follicles and irregular vascular structure commonly occur in wounded tissue which is often replaced by scar tissue. But with the activity of stem cells wounded tissue is replaced with normal tissue. In adults possible method for tissue regeneration is the placement of seeds of adult stem cell in the bed i.e. soil of wound bed. This will further allow the stimulation of stem cells to differentiation in the tissue bed cells. $^{7,8}$

Infertility: Differentiation of various germ cells i.e. precursor cells of oocytes and spermatozoa occurs due to human embryonic stem cells in mitotically inactivated porcine ovarian fibroblasts $(\mathrm{POF})^{8}$ which was evidenced by gene expression analysis. Even the Spermatozoon-like cells can be stimulated from human embryonic stem cells which could potentially treat azoospermia.

Haematopoiesis (blood cell formation): application of both of the hematopoietic adult stem cells as well as embryonic stem cells has provided insight into the possible mechanisms of blood formation. ${ }^{14}$

Hematopoietic stem cells (HSCs), which are popularly known as precursors of red blood cells can generate fully mature human red blood. In this process, HSCs are grown together with stromal cells which will create an environment that mimics the conditions of bone marrow which is the natural site for the growth of red blood cell. Moreover the Erythropoietin - a growth factor is added in the stem cells in order to complete terminal differentiation into red blood cells. ${ }^{15}$ Not only this ,even this technique can have potential benefits to gene therapy, blood transfusion, and topical medicine.

Cancer: For over 30 years chemotherapy has been popularly used in order to treat the conditions such as leukemia and lymphoma by the cytotoxic agents. But in chemotherapy most of the growing cells are killed as these agents cannot discriminate between the leukemia or neoplastic cells, and the hematopoietic stem cells within the bone marrow. Therefore in recent years umbilical cord blood stem cells have been used to treat cancer patients in order to mask the side effect of conventional chemotherapy strategies. The stem cell transplant attempts to reverse the donor's healthy bone marrow with reintroduction of functional stem cells so that replacement of the cells is done which occurred in the host's body during treatment. ${ }^{8,9,11}$

\section{CONCLUSION}

Due to continuous uncovering new facts and principles medical research is endlessly exciting in nature. The field of regenerative medicine is complex and multidisciplinary which offers an amazing power for body homeostasis, repair and regeneration. Hence existing knowledge about biological processes has to modify in the same way 
we think. But the progress will depend on the collaboration between clinicians and researchers from diverse fields.

\section{POTENTIAL IMPLICATIONS OF STEM CELLS IN DENTISTRY}

1. Regeneration of dental hard tissues

i. Enamel regeneration

ii. Dentine regeneration

iii. Cementum regeneration

iv. Regeneration of pulp

2. Bone regeneration

i. Regenerating of bone from autologous stem cells

ii. Implant associated bone regeneration

iii. Condyle regeneration

3. Periodontal tissue regeneration

4. Stem cells in sinus augmentation

5. Repair of cleft lip \& palate defects

6 . Regeneration of irradiated salivary glands

7. Peripheral nerve regeneration

8. Management of oral cancer

9. Whole tooth regeneration

\section{REFERENCES}

1. Haseeb N, Almas K. Stem cells and periodontal regeneration: present and future potential implications. JPDA 2010;19(2):78-86.

2. Lin N, Gronthos, Bartold PM. Stem cells and future periodontal regeneration. Periodontology 2000 2009;51: 239-51

3. Gupta AS, Gupta S, Singaraju S, Singaraju M. Role of dental adult stem cells in regenerative medicine.. Journal of orofacial research 2013;3(2):115-20.

4. Jamil K and Das GP. Stem cells: the revolution in current medicine. Indian journal of biotechnology 2005; 4: 173-85.
5. Bhateja S. Stem cells: Role in medical and dental Therapies. Journal of Orofacial Sciences 2012;4(1): 11-4.

6. Huawei Li, Roblin G, Liu H, Heller S. Generation of hair cells by stepwise differentiation of embryonic stem cells. PNAS 2003100 (23): 13495500

7. Dileep C, Suresh P, Khalilullah S, Nama S, Brahmaiah B, Desu PK. Stem cell: past, present and future- a review article. International Journal of Experimental Pharmacology2013; 3 (1) 7:11-20.

8. Jadon G, Diwaker AK, Bhadauria RS, Joshi SK. A Review on Embryonic Stem cell Information. IJARPB 2012; 2 (2):165-78.

9. Bhagyashree RP, Suraj MS , Bhusnure OG. Brief review of stem cell therapy. International Journal of Pharmacy and Biological Sciences 2013; 3(2): 2431.

10. Salazar DL, Uchida N, Hamers FPT, Cummings BJ, Anderson AJ. Human neural stem cells differentiate and promote locomotor recovery in an early chronic spinal cord injury nod-SCID mouse model. PLoS ONE 2012;5(8): e12272.

11. Yang R, Chen M, Lee CH, Yoon R, Lal S, Mao JJ. Clones of ectopic stem cells in the regeneration of muscle defects in vivo. PloS one 2010;5:e13547.

12. Eldor JI, Schuldiner M, Karsenti D, Eden A, Yanuka $\mathrm{O}$, Amit $\mathrm{M}$, Soreq $\mathrm{H}$, Benvenisty $\mathrm{N}$. Differentiation of Human Embryonic Stem Cells into Embryoid Bodies Comprising the Three Embryonic Germ Layers. Molecular Medicine 2000, 6(2):88-95.

13. Bluteau G, Luder H, Bari C. Stem cells for tooth engineering. Eur Cell Mater 2008;31;16:1-9.

14. Gupta AK. An overview on stem cell as a genetic medicine. Journal of Drug Delivery \& Therapeutics 2012; 2(2):39-47.

15. Miguel RS, Willenbring H. On the Origin of the Term- Stem Cell“". Cell Stem Cell2007; 1(1):35.
For article enquiry/author contact details, e-mail at: manuscriptenquiry.ihri@gmail.com 